sellers or other direct purchasers.

- Providing cash grants, allowances or "rebates" to academic institutions.

- Making direct payments to individuals other than for actual services rendered.

- Making contributions of equipment to academic departments, or paying for such equipment, in return for textbook adoptions.

- Making cash payments to third party suppliers of equipment or materials to institutions where the equipment or materials are not part of a textbook/ancillary materials package.

The AAP is a non-profit organization of more than 250 American publishing firms. The Association invites anyone who has a question about the adoption of any texts their members publish to get in touch with them at 220 East 23rd Street, New York, NY 10010-4686. Phone: (212) 689-8920; FAX: (212) 696-0131.

\section{Washington Restaurants: Annual Meeting Dining Guide}

\section{Nancy McManus}

Washington, D.C., is a city bristling with restaurants in all price ranges and serving a wide variety of ethnic and regional American cuisines. Many, many are very good and quite a few are first-rank. Dining in Washington is also the subject of numerous travel guide and magazine pieces, and is in any case much too vast a territory for adequate treatment here.

Consequently, we've elected to focus our restaurant feature on the areas accessible by walking from the Washington Hilton and Towers, and from the Sheraton and Omni-

Shoreham. These areas include Adams-Morgan, a very lively and ethnically diverse neighborhood to the east and southeast of the Hilton; the Dupont Circle area due south down Connecticut Avenue; and a segment of Connecticut Avenue to the north of the Sheraton and OmniShoreham.
The restaurant descriptions are excerpted, with permission, from three sources: The Washington Post Magazine, "Richman's Picks," by Phyllis C. Richman, September 16, 1990 (PR 1990), and "Richman's Choice," September 17, 1989 (PR 1989); and The Washingtonian magazine, "50 Very Best Restaurants," by Robert Shoffner, January 1991 (RS 1991). Finally, we have added some of the personal favorites of certain APSA staff members. The list is by no means complete, and hungry diners could do worse than simply to start walking, either north or south on Connecticut Avenue, or east across Florida Avenue or Calvert Street to the area around 18th and Calvert, and window-shop the many restaurants they will see along the way. Many have menus posted outside, and a quick peek through the door will usually provide a good indication of the atmosphere and level of dressiness to be found inside.

Good luck, and bon appetit!

$(\mathbb{C}=$ inexpensive; $\$=$ moderate, $\$ \$$

$=$ expensive, $\$ \$ \$=$ very expensive)

\section{Adams-Morgan Neighborhood}

\section{On Calvert Street:}

Mama Ayesha's Calvert Restaurant, 1967 Calvert Street, NW, 232-5431

(c)

". . . a relic, a museum of itself, seemingly unchanged in the last 32 years except that instead of Mama being there in person the walls are covered with her photos. The two dining rooms of the Arabic restaurant are a little frayed from their early days, and the sort-of-wood paneling doesn't have quite the dash it once had.

"All that lack of modernization works to our advantage. Most platters are still less than $\$ 7.00$, for generous portions, and it would be hard to spend more than $\$ 15$ a person even after plenty of wine or beer, thick sweet coffee, and dessert.

"This is a plain place with a standard menu and unadorned plate of food. ... The lemon and garlic are balanced in the hummus with just enough sesame paste so that no one taste predominates. The baba ghanouj is as good as anywhere you might find it. And a sesame-paste dip with chunks of tomato and cucumber, called Arabian Salad, is particularly refreshing. With these appetizers comes a plate of white Syrian cheese, ultra-salty black olives and a basket of warm pita bread. ... In all, Calvert Restaurant is more than a landmark, it is one of the most reliable of bargain restaurants as well as a trip to another time and place." (PR 89) Sun-Thurs 11:30 a.m. to midnight. Credit cards.

\section{On Florida Avenue:}

El Tamarindo, 1785 Florida Ave., NW, 328-3660 (\$)

"Washington has become admired as a city with some great restaurants, but equally important it has become a city with some great $\$ 5$ dinners. $\mathrm{El}$ Tamarindo is a prime source. And while your dinner bill could climb to the $\$ 15$ stratosphere, my favorite dishes cost under \$3. Salvadoran restaurants have taught us to love pupusas, those thick, soft cornmeal tortilla sandwiches with white cheese, bits of bacon, or both. They ooze cheese with each cut of the forkand cost a mere $\$ 1.25$. Two or three would be enough for a meal. But if you don't want to make a whole meal of pupusas, there is a large platter of yucca con chicharron for $\$ 2.95$. The yucca is a little drier and more flavorful than a potato, fried so that it is more crusty than even the best french fries. And the chicharron is cubes of pork cooked so long that they are crisp straight through. The whole is topped with a layer of fiery, tart Salvadoran cabbage salad.

"The menu has plenty more, from fajitas to enchiladas and burritos. They are good too, particularly the shredded beef burritos with their highly seasoned ropy meat that brings to mind the Cuban stew, ropa vieja. All the food has plenty of tang, as you can tell from the first bite of the chips dipped with the cumin-scented salsa.

"Along with the bargain-priced food comes efficient, bustling service, a dining room and a closed-in porch, .... an underlying rhythm of Latin music and a lively and eclectic crowd." (PR 90) Mon-Thurs 11-2 a.m.; Fri 11-5 a.m.; Sat-Sun 10-5 a.m. Credit cards. 
On Columbia Road:

Cafe Atlantico, 1819 Columbia

Road, NW, 575-2233 (\$)

"The casual café format here is appealing to bar patrons who want to snack on the excellent conch or cod fritters as well as to diners who are satisfied with a main course and a glass of wine, to say nothing of those inclined to order the traditional three courses and a bottle of wine. With the exception of its tame 'jerk' chicken, the food from Café Atlantico's kitchen demonstrates its good grasp of Caribbean flavors. The frying is impeccable, and whether as a bar snack or a first course, the shrimp-and-potato croquettes and the yucca fritters are irresistible. Main courses are preceded by deliciously peppery little biscuits meant to be spread with an accompanying blackbean purée. Among the main courses, some of the most enjoyable have included highly spiced sausage served with braised cabbage; pork loin with a glaze of rum and brown sugar; a mild curry of lamb; and a fine dish of octopus fricasseed in red wine." (RS 91) Sun-Thurs 5:30-11 p.m.; Fri-Sat 5:30 p.m.-12:30 a.m. Credit cards.

El Caribe, 1828 Columbia Road, NW, 234-6969. (\$)

"Several things you can count on at El Caribe: The service is endearing, the margaritas are freshly tart, and the closer the dishes are to their peasant roots the more wonderful they are likely to be. There is a casserole of well-browned, crusty boneless cubes of pork with a delicious array of ripe and green plantains and root vegetables. $\mathbf{A}$ tongue stew is meltingly soft in a tangy and spicy tomato sauce. There is a long list of casseroles of chicken and lamb, beef and seafood, and if they include olives, peppers and such savories, they will show off $\mathrm{El}$ Caribe's talents.' (PR 89) MonThurs 11:30 a.m.-10 p.m.; Fri 11:30 a.m.-11 p.m.; Sat noon-11:30 p.m.; Sun noon-10 p.m. Credit cards.

\section{La Plaza, 1847 Columbia Road,} NW, 667-1900 (\$)

Spanish and Mexican cuisine, sister to Lauriol Plaza (below); terrace dining. 11 a.m.-11 p.m. Credit cards.
On 18th Street, heading South:

Red Sea, 2463 18th St., NW, 483-5000. ( $4-\$)$

One of several Ethiopian restaurants in Adams-Morgan, a favorite of APSA staff. 11 a.m.-11 p.m. Credit cards.

Massawa, 2341 18th St., NW, 483-6661. (\$-\$)

Ethiopian. Noon-midnight, every day. Credit cards.

Millie \& Al's, 2440 18th St., NW, 387-8131. (\$-\$)

For beer and burgers, and a lively atmosphere. Fri-Sat noon-2 a.m.; other days 4 p.m.-2 a.m. No credit cards.

I Matti, 2436 18th St., NW, 482-8844. (\$)

“ 'The Crazies,' as its name translates from the original Italian, is thriving. Why? Because its café format accommodates different appetites while making the single diner who orders a pizza or a plate of pasta just as welcome as those who ask for four-course dinners and bottles from I Matti's impressive wine list.

"The menu, from soups and pasta to appetizers and main courses, is rustic in spirit: squares of grilled polenta topped with various garnishes; wide noodles tossed with a rich sauce of rabbit; and venison stewed in red wine and served with creamy polenta. Most of the main courses are substantial enough to serve as one-plate meals, although I Matti's antipasto and dessert carts can test the discipline of the dietconscious." (RS 91) Mon-Thur noon-11 p.m.; Fri-Sat noon-11:30 p.m.; Sun 11:30 a.m.-9:30 p.m. Credit cards.

Meskerem, 2434 18th St., NW, 462-4100. (\$)

"Although Meskerem's list of dishes is like those offered by most local Ethiopian places, this restaurant's cooking is consistently above average. A representative introduction to the pleasures of Ethiopian dining here would include kitfo, the assertively spiced native version of steak tartare; shrimp wat, a currylike dish whose fiery sauce emphasizes the natural sweetness of the shrimp; lamp alecha, a gently sea- soned stew with an appealing hint of sweetness; and tibs, a sauté of beef with fresh green chilies."' (RS 91) Mon-Thur 5 p.m.-midnight; Fri-Sun noon-midnight. Credit cards.

La Fourchette, 2429 18th St., NW, 332-3077. (\$)

"Many restaurants serve bouillabaisse. Amend that: Many restaurants serve what they call bouillabaisse. And what La Fourchette serves under that name might be questioned by purists, since it isn't made with Mediterranean fish. But it comes closer than any I recall locally, by virtue of its flavor. And it is a delicious bargain at $\$ 14.95$. . . .

"La Fourchette recalls France with more than its bouillabaisse, of course. The murals on the old brick walls, the sidewalk tables, the atmosphere of a Left Bank bistro are a start. Then there is the menu: warm, rich garlic sausage and potatoes drenched in vinaigrette, house-made pâté or onion tart, puff-pastry lunchi entrees filled with ham and cheese or zucchini, and a long list of daily specials. La Fourchette serves homey stews as well as refined mousses and sauces. Its food has a personal, handmade quality, right down to the desserts of ground-almond cake with chocolate ganache and liqueurmarinated orange wedges crowned with candied peel." (PR 90) Mon-Fri 11:30 a.m. $-10: 30$ p.m.; Sat. 4 p.m.midnight; Sun 4-10 p.m. Credit cards.

Fish, Wings, \& T'ings, 241818 th St., NW, 234-0322. (c)

'It's the Jamaica of our dreams, this bright, splashy 'mini kafe' with its whimsically painted tables and its giant kitchen stools. The island music, the melon, pineapple and ginger scents of the fruit punches, the curry kick of the main dishes and the soul-warming rice and peas compensate for the lack of a beach in Adams-Morgan. For less than $\$ 10$ you can feel like you're on vacation.

"The menu is short: a few fiery chicken dishes, several vinegary escoveitched fish, curries of oxtail and goat, shrimp creole and perhaps a chicken and a fish from the grill, all buried in bright and spicy sauces, accompanied by carrot-raisin salad and rice-and-peas.

"It's hard to pick a star out of 
this menu, small as it is. But no dish is better than the curry ginger wings, their sauce as yellow as the summer sun (and eqully hot), so good that you'll risk tinting your fingers for the day in order to pick up these morsels of chicken and do them justice. In all, though, it is a full meal that would capture all the stars: curry ginger wings, gingery pineade and a slice of rich, nutty chocolate banana cake oozing with chocolate chips and buttery crumb." (PR 90) Mon-Thur noon-10 p.m.; Fri-Sat noon-11 p.m. Closed Sunday. AE only.

Belmont Kitchen, 2400 18th St., NW, 667-1200 (c-\$)

Lunch 11:30 a.m.-2 p.m. Tues-Fri; 11:30 a.m.-3 p.m. Sat; Sunday Brunch 11:30 a.m.-3 p.m.; Dinner 5-10 p.m. Closed Monday. Credit cards.

Kalorama Cafe, 2228 18th St., NW, 667-1022. (4-\$)

Lunch 11:30 a.m.-3 p.m.; Dinner 6-10 p.m., till 11 p.m. weekends. No credit cards.

Le Tam Tam, 1910 18th St., NW, 483-0505. (\$-\$)

Lunch noon-2:30 p.m.; dinner 5:30, closing varies. Credit cards.

Straits of Malaya, 1836 18th St., NW, 483-1483. ( $\$-\$)$

Lunch noon-2 p.m.; Dinner 5:3010:30 p.m., till 11 p.m. weekends. Credit cards.

A Touch of Lemon Grass, 1805 18th St., NW, 387-8047. (\$-\$)

A very pleasant Thai restaurant. Lunch noon-2:30 p.m.; Dinner 510:30 p.m. Credit cards.

Lauriol Plaza, 1801 18th St., NW, 387-0035. (\$)

"Such exquisite decisions! I greatly admire Lauriol Plaza's margaritas, but almost nobody else makes pisco sours, so which shall I drink tonight? The dining room is pretty, but sitting outside is one of the nicest possible urban moments. And even the food -will it be subtle classical. Spanish or the spice of Mexican? Lauriol Plaza combines both ethnicities with neither suffering.

"Usually I opt for outdoors, leaving the noisier inside for days when al fresco can't be considered. Similarly, since margaritas are ubiqui- tous, we generally have a pitcher of pisco sours at our table. As for the Spanish/Mexican dilemma, I like to dine with enough people so we can sample both.

"Lauriol Plaza's gambas al ajillo are plump and juicy shrimp, awash in melted butter thick with mild fried garlic, parsley and the sweetness of sherry. Skip the chips-this dish deserves one of Lauriol Plaza's dense French rolls to sop up the sauce. For a lighter appetizer, ceviche is carefully balanced in its tartness, the fish is fresh, and the hot chilies are restrained. There are also mussels with sherry, ginger and garlic or the basic nachos and quesadillas. Main dishes include seafood combinations as stews, enchiladas and paella; beef dishes from tongue with madeira to fajitas and 14-ounce sirloins; chicken and duck as well as Cuban masitas de puerco-cubes of pork longcooked in bitter orange juice. Mexican dishes are some of the freshest and zestiest in town, the tamales fiery and the enchiladas stuffed with tangy shredded meat. . . . My favorite continues to be the duck, whether served with a delicate bitter orange glaze or with olives. Lauriol Plaza accompanies its main dishes with glistening white rice and stewed black beans.

"Dinner at Lauriol Plaza can climb above $\$ 30$, but it need not, for there are plenty of main dishes for less than \$10. In all, with such lively and efficient service, such spirited cooking and such a charming downtown corner, Lauriol Plaza would be hard to resist even if it weren't a bargain." (PR 90) Mon-Sat noonmidnight; Sunday 11 a.m.-midnight, Sunday brunch until 3 p.m.

\section{At 17th and R Streets:}

El Bodegon, 1637 R St., NW, 667-1710. (\$-\$\$)

". . . one of Washington's oldest ethnic restaurants, and for good reason. It offers a lot of entertainment-guitarist, flamenco dancers, wine-guzzling ceremony-and decent food. And if you know your way around, it does even better than that. ... Meander through the tapas listpotatoes in a thick garlic mayonnaise, bay scallops with mushrooms in a picquant buttery sauce, sliced ham aged overhead in that very tapas bar, ham and chicken croquettes, mussels bathed in onions, garlic and parsley, or shrimp buried in garlic and butter. Or make a meal of standard Spanish paella or fish in green sauce. ... The service is very Spanish and generally charming, the rooms are cozy, and there is all that entertainment." (PR 90) Lunch Mon-Fri 11:30 a.m.-2:30 p.m.; dinner MonThur 5:30-10:30 p.m., till 11 p.m. Fri and Sat; closed Sunday. Credit cards.

La Fonda, 1639 R St., NW, 232-6965. (\$)

An extremely pleasant Mexican restaurant next door to El Bodegon. Lunch 11:30 a.m.-3 p.m.; dinner 5-11 p.m., till midnight weekends. Credit cards.

Connecticut Avenue, North to South, with a few branches.

Mrs. Simpson's, 2915 Connecticut
Ave., NW, 332-8300. (\$-\$\$)
“. . . The food tends to be light, highly seasoned but uncomplicated, and very attractive. So is the dining room-particularly in the evening when the candlelight sparkles in the mirrors. The wine list is intelligent and reasonably priced, the service is solicitous and polished enough that it charms without intruding. Mrs. Simpson's offers great urbanity at a modest price. It is a very, very civilized restaurant." (PR 90) Sun-Thur 5:30-9:30 p.m.; Sat til 10 p.m.; Sunday brunch 10:30 a.m.-2:30 p.m.

Petitto's, 2653 Connecticut Ave., NW, 667-5350. (\$)

A very nice blending of traditional and modern Italian fare, including pizzas, in pleasant surroundings. Lunch Mon-Fri 11:30 a.m.-2:30 p.m.; dinner Mon-Sat 6-10:30 p.m.; Sunday 5-9:30 p.m. Credit cards. Cafe Petitto, its more informal younger sister (1724 Connecticut Ave., NW, 667-5350), is open every day from 11:30 a.m. till 10:30 p.m. Credit cards.

Nora, 2132 Florida Ave., NW, 462-5143. (\$\$)

"... What sets Nora apart is the attention it pays to using herbs and produce grown organically, procuring meats raised without antibiotics and making breads and pastas with organic flours. ... . While the menu 
changes daily, it always includes a soup such as spinach and roquefort with a chicken stock base, plus home-cured gravlax with Vidalia onions; probably the best caesar salad in town; grilled fish with a variety of salsa, vinaigrettes or sauces; fettucine with perhaps vivid bits of vegetables and a plenitude of lobster; and a curry. ... The happiest surprise on the menu [is] an organic vegetarian plate that for once doesn't make vegetarians feel like wall-flowers. This one changes with the seasons, but contains about half a dozen marvels such as buttery, fleshy grilled portabella mushrooms, golden saffron risotto, a sparklingly dressed lentil salad and such green vegetbles as asparagus and turnip greens. It is priced right up there with the meat dishes . . . but deserves to be so, for it is a star, not an afterthought.' (PR 90) Mon-Thur 6-10 p.m.; Fri-Sat 6-10:30 p.m. Closed Sunday. No credit cards.

Suzanne's, 1735 Connecticut Ave., NW, 483-4633. (\$)

Upstairs, a cafe; downstairs, a carryout. The freshly baked desserts are outstanding. Lunch Mon-Sat noon-2:30 p.m.; Dinner Tue-Thur 6-10:30 p.m., till 11:30 p.m. Fri-Sat. Closed Sundays and for dinner Mondays. Credit cards.

City Lights of China, 1730 Connecticut Ave., NW, 265-6688. (\$)

Mon-Fri 11:30 a.m.-10:30 p.m.; Sat-Sun noon-10:30 p.m. Credit cards.

Timberlake's, 1726 Connecticut Ave., NW, 483-2266. (\$)

Very nice American pub food. Sun-Thur 11:30 a.m.-2 a.m.; till 3 a.m. on Fridays and Saturdays. Credit cards.

Childe Harold, 1620 20th St., NW, 483-6700. ( $\mathbb{C}-\$$ )

Very good burgers, fancy hot sandwiches, omelets, and specials for lunch. Sun-Thur 11:30 a.m.-2 a.m.; till 3 a.m. Fridays and Saturdays. Credit cards.

Vincenzo, 1606 20th St., NW, 667-0047. (\$\$)

"Change comes slowly at Vincenzo, the precursor to Washington's current group of authentic Italian restaurants. Last year it completed a renovation that doubled its seating capacity; now it has refreshed its menu with new dishes and a page devoted to poultry and meat specialties. Considering that the core of its regular clientele patronizes Vincenzo for the superb seafood, one wonders how many of them will forsake the grilled Dover sole or the fritto misto di mare for osso buco or veal kidneys sautéed with mushrooms.

"Almost eleven years after opening, Vincenzo remains the best seafood restaurant in D.C. The quality of its seafood is uncompromising, and the kitchen's work is consistently precise. To emphasize the flavor of the freshest seafood available, the menu restricts its offerings to the simplest Italian preparations. On a menu composed each day according to market availability, some of the current highlights include fish ravioli in tomato sauce, risotto with shellfish, baked stuffed sea bass, fritto misto di mare, and grouper with green sauce."' (RS 91) Mon-Fri noon2 p.m.; Mon-Sat 6-10 p.m.; Sundays 6-9 p.m. Credit cards.

Kramerbooks and Afterwords, 1517 Connecticut Ave., NW, 387-1462. (\$-\$)

This bookstore with cafe attached is a Washington institution, one of the very few establishments open all night, albeit on weekends only. Browse through the bookstore first, or while you wait for a table either indoors or on the sidewalk if the weather is nice. Come early in the morning for a croissant and cappucino, at lunch for a delicious composed salad or inventive sandwich, or anytime you want to be alone in a crowd. Solo patrons are always welcome, and it might be a very good place to strike up a conversation with a stranger. Mon-Thur 7:30 a.m.12:45 a.m.; 7:30 a.m. Friday till 12:45 a.m. Sunday (i.e., all night Fridays and Saturdays).

Verdi, 2014 P Street, NW, 467-4466. $(\$ \$)$

The newest entry in Washington's group of outstanding modern Italian restaurants. Lunch 11:30 a.m.-2:30 p.m. Mon-Fri; Dinner 5:30-10:30; till 11 on Fridays and Saturdays. Credit cards.
Sala Thai, 2016 P St., NW, 872-

1144. (\$)

"While American and European restaurants are finally catching on to the fact that diners want more casual restaurants at moderate prices without sacrificing food quality or style, Thai restaurants have already gotten the message. Sala Thai is no fancier or more expensive than a cafe, but its color scheme is electric, its service is attentive, and its food is as brilliant as any full-dress restaurant.

"The best of Sala Thai is its seafood, and the best time of year to dine here is in soft-shell crab season. If there are soft-shells, think green. They can be ordered lightly crisped with a creamy pale green curry sauce that is astonishing: Its flavor is of myriad spices and chilies, but it is delicate enough to allow the crab taste to emerge. This is a curry sauce tasted through a veil-all the color, the aroma and the depth without the numbing intensity. Since most of the year is not soft-shell season, also think red-the sunset-colored curry peanut sauce that dresses shrimp. The dish is a stunner, with pink shrimp against the red-gold sauce and dark green whole leaves of basil. Once again the flavors are dashing, but the firepower is only a background for the subtle shrimp.

"There is plenty more to admire on this long menu, from lemony and incendiary cellophane noodles tossed with shrimp and pork as an appetizer as refreshing as a salad, to addictive juicy little skewers or pork satay, to shrimp in eggroll wrappers called Pinky in the Blanket. Even a neonred sweet-and-sour seafood is of serious quality." (PR 90) Lunch Mon-Fri 11:30 a.m.-2:30 p.m.; dinner Sun-Thur 5-10:30 p.m., Fri till 11 p.m.; Saturday noon-11 p.m. Credit cards.

Pan-Asian Noodles \& Grill, $2020 \mathrm{P}$ St., NW, 872-8889. (c-\$)

"One of Washington's success stories in recent years has been PanAsian Noodles \& Grill, which started out as one neon-decorated dining room and has spread to two restaurants. The secrets to its success have been an interesting variety of Asian dishes at modest prices with gracious service in a bright modern environment. The menu is small but encom- 
passes meal-size bowls of noodle soups, entrees ranging from China's lo mein and chow foon to Thailand's pud thai. It also features a few grilled dishes from appetizer brochettes to the day's fish. And several nationalities' versions of spring rolls have been added, such as cha gio and egg rolls." (PR 90) Lunch MonSat 11:30 a.m.-3 p.m.; dinner every day 5:30-10:30 p.m. Credit cards.

Obelisk, 2029 P St., NW, 872-1180. (\$\$)

"Chef Peter Pastan's elegantly understated restaurant will not please diners who expect a great range of dishes, but chef Pastan's limitedchoice, fixed-price menu attracts Italophiles who vie nightly for a table in this dining room with fewer than 40 seats. The four- or five-course menu for $\$ 32$-one is given the option of ordering cheese or dessert or bothusually means you choose from two first and second courses, three main courses, and two desserts. The meal begins with an unlisted hors d'oeuvre - frequently thin slices of toasted bread spread with a smooth paste of chicken livers or finely minced olives.

"Pastan's menu changes nightly and is determined by both the seasonal market and the chief's whim. Inspired by dishes he learned to cook while working in the kitchen of a small, rural restaurant in northern Italy, his cuisine is as authentic as the crusty, chewy, house-baked bread that complements each meal.

"Obelisk's short wine list is a model of thoughtful selection and fair pricing. The gentleman who serves in the dual capacities of host and captain is well-versed in the characteristics of each bottle and makes sound recommendations." (RS 91) Dinner Mon-Sat, 6-10 p.m. Credit cards.

Bacchus, 1827 Jefferson Pl., NW, 785-0734. (\$-\$\$)

"Lebanon has long been regarded as having the finest cuisine in the Middle East, and ... Bacchus ... upholds that tradition. . . . Newcomers ... should be pleased with the fluffy pilafs studded with almonds and pine nuts and topped with lamb or chicken: the stuffed cabbage; and a classic kafta mechwi, generous serving of sausage-shaped beef kabobs made from a mixture of ground beef, minced onions, and parsley. But the appetizers are so good that Bacchus regulars sometimes forgo the main courses in favor of dining on maza, a large assortment of appetizers, all of which are brought to table at the same time. The highlights of a maza composed from this menu include stuffed baby eggplant sauced with pomegranate; spicy Turkish sausage; eggplant salad; deep-fried pastry cylinders stuffed with meat; stuffed grape leaves; and a splendid version of hummus, in which the chickpea puree is topped with ground lamb, almonds, and pine nuts." (RS 91) Lunch Mon-Fri noon-2:30 p.m.; dinner 6-10 p.m., till 10:30 on Fridays and Saturdays. Credit cards.

Tabard Inn, 1739 n St., NW, 833-2668. (\$-\$\$)

"Fresh is becoming a tired word in the restaurant world, but the Tabard Inn brings it back to life. Lunch in the garden is one of Washington's hidden natural assets, and the menu takes advantage of the best of our countryside.

"One dish tells the story: Grilled tuna is a cliché these days, and it is a fish that is often maligned. But at the Tabard Inn it is slightly crusty and thick enough that the center is tender and moist. One day it was stuffed with gingered shrimp, an accent rather than a distraction, and its topping of pineapple vinaigrette was fruity without being too sweet. The tuna was positioned on a bed of couscious to absorb the juices. A sharply vinegared salad of julienned raw vegetables added crunch.

"The Tabard Inn's menu sounds colorful-white and red gazpacho swirl, beet and red onion salad, twotoned salad of smoked and fresh salmon with opal basil vinaigrette. And the inn goes to special lengths to get naturally raised beef and additive-free bacon for its burgers, even brings vegetables from its own farm and makes its own potato chips.

"This kitchen doesn't get too complex, it doesn't strive too hard. Pastas, salads, chicken, fish and a couple of beef dishes make up its menu, with no such pretentions as beurre blancs or wine sauces. This is down-to-earth real American cooking of the 80s." (PR 89) Breakfast, Mon-Fri 7-10 a.m.; Sat-Sun 8-10 a.m.; lunch Mon-Fri 11:30 a.m.-2:45 p.m.; Saturday 11 a.m.-2:45 p.m.; Sunday brunch 11 a.m.-2:45 p.m.; dinner 6 p.m., closing varies. Credit cards.

City Cafe, 2213 M St., NW, 797-4860. (c)

Open noon-10:30 p.m.; till 11 p.m. Saturdays; closed Sunday. Credit cards.

Taj Mahal, 1327 Connecticut Ave., NW, 659-1544. (\$)

Very nice Indian food. Lunch noon-2:30 p.m. Mon-Fri; dinner every evening 5:30-9:30 p.m.

The following three restaurants are among the most acclaimed of the new-wave eateries in the city. All are quite expensive, and each is worth it.

I Ricchi, 1220 19th St., NW, 835-0454. (\$\$-\$\$\$)

'.. . One can enjoy Francesco Ricchi's cuisine at its best by choosing from the Tuscan specialties that comprise most of the menu's offerings. Save the seafood orders for other Italian restaurants; the best dishes here are soups that resemble stiff vegetable porridges, pastas sauced with duck or hare, meats and poultry and game from the woodfired grill, roasted specialties from the wood-burning oven, and la scottiglia d'arezzo, a combination plate of assorted meats braised in red wine, tomato, and lemon." (RS 91)

Lunch Mon-Fri 11:30 a.m.-2:30 p.m.; dinner Mon-Thur 5:30-10:30 p.m.; till 11:00 p.m. Friday and Saturday. Credit cards.

Galileo, 1110 21st St., NW, 293-7191. (\$\$-\$\$\$)

". . . Last summer Roberto Donna moved Galileo a few blocks into expansive premises and gained a kitchen large enough for his talent. Donna is a proud northern Italian, but the new Galileo's menu reveals him to be a gastronomic tourist at heart. A contentious party of Italophiles, each wanting to satisfy his or her hunger at one or another of our new breed of authentic Italian restaurants, could all find happiness at Galileo.

"Its breads are . . . impressive ... and offered in (great) variety; its fish 
is of the same high quality as that served at Vincenzo, and served in almost as many different ways; and its rich northern-Italian poultry, meat, and game dishes are balanced by some alternative choices that are as uncomplicated as the best served at I Ricchi.

"With a wine list of comprehensive length, and a comfortable dining environment, the new Galileo captures the exuberance of Italian cooking because its floor staff conveys the feeling that a meal here is a celebration. This is a group of servers with a sense of enthusiasm about the wonderful food they are serving." (RS 91) Lunch Mon-Fri 11:30 a.m.2 p.m.; dinner Mon-Sat 5:30-10:30 p.m.; Sundays 5-9 p.m. Credit cards.

Sam \& Harry's, 1200 19th St., NW 296-4333. (\$\$-\$\$)

"The hottest new restaurant of the year is Sam \& Harry's, a classic American steak house. The keys to its early popularity are superb topprime beef purchased from the same Chicago purveyors that supply the original Morton's and all of its branches; selected dishes that provide an alternative to the cholesterol overload of the porterhouse and the prime rib; a floor staff which understands that you encourage return business by treating newcomers with all the attention other restaurants reserve for long-time regulars; and a long, handsome bar that usually remains civilized even when it's packed.

"Recommended first courses include fried calamari and miniature crab cakes. Plan a first visit to Sam \& Harry's when your diet allows you to indulge in beef, because here the porterhouse and the prime rib are better than at any local restaurant except Morton's. Alternatives are stuffed baby chicken, excellent pork chops, simply grilled fish, and giant lobsters that the kitchen will split for two diners who don't want to tackle one of these leviathans alone." (RS 91) Lunch Mon-Fri 11:30 a.m.2:30 p.m.; Dinner Mon-Sat 5:30-11 p.m. Credit cards.

\section{Short Courses Include New Leading Scholar Series for Graduate Students}

Each year in conjunction with the annual meeting APSA offers a selec- tion of short courses. The courses provide an opportunity for members to develop and enhance their knowledge about a field and to invigorate their teaching and research.

\section{Leading Scholar Series}

This year Professor Aaron Wildavsky of the Graduate School of Public Policy at the University of California at Berkeley will inaugurate an annual Leading Scholar Series of short courses exclusively for graduate students. The series will focus on topics relating to professional life as a political scientist. Professor Wildavsky, a former president of APSA, will talk with graduate students about "the organization of scholarly work," drawing on the observations in his recent book Craftways. The course is scheduled for Wednesday afternoon, August 28, 1991. More details are provided on the registration form at the back of this issue of $P S$.

\section{A Spectrum of Data Resources in Four Archives}

The short course program planned for this year will also offer a fourpart Data Resources sequence featuring presentations by the National Archives, the National Security Archives, Vanderbilt University's Television News Archive, and Purdue University's Public Affairs Video Archives, which holds the research archives of C-SPAN Programming.

Members can register for either a half or whole day of the Data Resources course. Details of the time and sequence of the course can be found in the back of this issue of $P S$ along with the preliminary program for the Annual Meeting. A registration form and more detailed descriptions of the courses can also be found there.

\section{National Archives}

The National Archives is the repository of federal government agency records. It serves as the official record keeper of the national government's history, and these records have assisted the general public and particular groups in various kinds of research. Archivists from the National Archives Records Administration will present a session on research and federal records at the agency. Topics will include: reference services, access, and record holdings. This session will discuss important and critical aspects of the National Archives regarding its resources, highlighting holdings of special interest to political scientists.

\section{National Security Archives}

The National Security Archive is a nonprofit research institute founded in 1985. The Archive provides scholars with unclassified and declassified government documents. As a leading advocate and user of the Freedom of Information Act (FOIA), the Archive with the help of pro bono representation by Washington law firms broke down the fee barrier used by agencies as a threat against reporters and researchers to deter them from using the FOIA.

In other cases the Archive forced the release of thousands of pages of previously classified documents: the complete list of all documents declassified by the CIA, the Pentagon's index of FOIA requests, the cable traffic between the State Department and the embassy in Managua throughout the period of the Contra war, the internal embassy critiques of the U.S. relationship with Ferdinand Marcos, planning documents for a second Iran rescue mission, and the FBI's internal memos on the attempted recruitment of librarians as informants. More about the development of the Archive and its special holdings will be presented as part of the data resources short course.

\section{Vanderbilt Television News Archive}

The Vanderbilt Television News Archive will profile the Archive resources in terms of both teaching and research. The presentation's center of gravity will lean heavily toward research. Two types of data are generated in the Archive: those on videotape and those to be found in the Television News Index and $A b$ stracts, which have increasingly been used as a source of free-standing data. Past research using Archive data as well as research currently underway will also be discussed.

\section{Public Affairs Video Archive}

The Public Affairs Video Archive will highlight using the C-SPAN Programming Archive for both teaching and research. In addition to the complete videotape record of U.S. House 